\title{
Pro-Poor Growth in Different Economic Sectors in Iran: A Zenga Index Approach
}

Mohammad Sharif Karimi ( $\nabla$ sharifkarimi2@yahoo.com )

Razi University https://orcid.org/0000-0002-5967-6756

\section{Sohrab Delangizan}

Razi University of Kermanshah: Razi University

Elham Heshmati daiari

Razi University of Kermanshah: Razi University

\section{Research}

Keywords: Pro-Poor Growth, Gini Coefficient, Poor, Poverty Line, Lorenz Curve, Iran

Posted Date: January 21st, 2021

DOI: https://doi.org/10.21203/rs.3.rs-150972/v1

License: (1) This work is licensed under a Creative Commons Attribution 4.0 International License. Read Full License 


\title{
Pro-Poor Growth in Different Economic Sectors in Iran: a Zenga Index Approach
}

Mohammad Sharif Karimi ${ }^{1}$

Sohrab Delangizan ${ }^{2}$

Elham Heshmati daiari ${ }^{3}$

\begin{abstract}
Poverty is one of the most important issues in developing countries; thus, poverty and poverty reduction have always been a concern for nations. This unbearable social phenomenon, which must be controlled, is out of control in most of developing countries. This study aimed to develop coordination and interrelation between economic growth, inequality, and poverty in Iran. Therefore, this study was conducted to determine how much economic growth reduces poverty by calculating pro-poor growth index (PEGR) for service, industry, and agriculture sectors in urban and rural areas in Iran from 2005 to 2018. Besides, it assessed the effect of changes in the average income and the distribution of income on poverty. We identified economic sectors with pro-poor growth. The findings of the research indicated that there was pro poor growth just in the rural service sector in Iran. In addition, although the distribution effects decreased poverty in the other sectors, total poverty increased under the period because of the negative growth. Also, the Zanga index results indicate that inequality has decreased in all sectors during the period.
\end{abstract}

Jel Classification: O47, D33, I32, O15, $\mathrm{D}_{63}$

Keywords: Pro-Poor Growth, Gini Coefficient, Poor, Poverty Line, Lorenz Curve, Iran

\footnotetext{
${ }^{1}$ Assistant Professor in Economic, Faculty of Economic and Entrepreneur, Razi University, Iran. E-mail: s.karimi@razi.ac.ir

${ }^{2}$ Associate Professor in Economic, Faculty of Economic and Entrepreneur, Razi University, Iran. E-mail: delangizan@razi.ac.ir

${ }^{3} \mathrm{PhD}$ student in Economic, Faculty of Economic and Entrepreneur, Razi University, Iran. E-mail: el.heshmati@yahoo.com
} 


\section{Introduction}

Poverty is one of the problems of human communities, and its reduction has always been one of the main objectives of government policies. Overall growth plays a crucial role in achieving this goal, but income inequality affects the speed at which economic growth leads to poverty reduction. The most important challenge for policymakers in designing poverty reduction policies is establishing a link between macroeconomic and microeconomic fields. A key question explored in the early literature was whether growth would result in lower inequality as countries advanced through economic development stages. Some studies estimate a positive relationship between economic inequality and economic growth and studies that estimate a negative relationship. A direct relationship between economic growth and changes in poverty cannot be defined, and economic growth does not necessarily lead to poverty reduction. Thus the impact of different economic growth policies on poverty is not the same due to the differences in their impact on household income distribution. Economic growth does not necessarily lead to poverty reduction. Therefore, as poverty reduction depends on economic growth and income distribution, it is necessary to define poverty reduction policies based on each economic sector's characteristics. Because of the differences in characteristics of different sectors of the economy and the extent of the initial inequality, economic growth has different effects on poverty reduction. Poverty reduction is the first goal of the Millennium Development Goals (MDGs) and is the biggest global challenge. In the second half of the twentieth century, countries that have been able to reduce poverty have benefited from continued growth in the long run. Nevertheless, there are also some efforts to reduce poverty in the short term. To address this problem in Iran and solutions have been proposed in the development program as 
a part of the economic restructuring plan. Also, the poverty reduction bill has been prepared many times, but none of these has been converted into a well-documented operational program. Since capital resources are limited in each country, achieving development goals such as increasing economic growth and reducing poverty requires focusing on specific economic sectors. Through investing in those sectors, there will be more chances and potential for realizing the desired goals.

In recent years, Iranian economics face up with increasing poverty rates, and this phenomenon is a critical issue in this country so that this paper proposes a measure of pro-poor growth derived from the idea of "poverty equivalent growth rate (PEGR). In addition to extending a Zenga index approach to measure poverty and studying pro-poor growth in Iran, which is the first study in this area in Iran. Zenga (2007) proposed a new methodology to both plot and measure Inequality, and this methodology gives more complete information than the Gini index. Moreover, in this study, we test an empirical model of the evolution of the aggregate (urban plus rural) poverty measures at provinces level in Iran. In addition, to helping us understand what makes growth in a given sector of the economy more pro-poor we divided sectors into industry, service, and agriculture sector. The results for each of them will report separately. Therefore, an attempt was made to determine the best economic sector for investing. It not only helps to achieve economic growth but also will be more likely to benefit the poor. The rest of the paper is structured as follows. Section 2 reviews the literature as well as other related previous study attempts. Section 3 includes Theoretical foundations. Section 4 presents the analytical and research methods overview of the evidence, and methodology. Section 5 discusses and explains Data the empirical findings. The following section contains conclusions.

\section{Literature Review}

The relation between growth and inequality was debated extensively in 1955 by Simon Kuznets. He found an inverted-U Shaped between per capita income and inequality based on a cross-section of countries: as per capita income rises, inequality first worsens and then improves also this hypothesis was confirmed by a number of studies, For instance, Kravis (1960), Oshima (1962), Paukert (1973), Ahluwalia (1976), and Ram (1988). But as we know the relationship between growth and poverty is a complex. It is also determined by the level and changes in inequality and the pro-poor growth debate has arguments by Chenery and Ahluwalia (1974). Recently Pro-poor growth is concerned by new studies in this area which more recently and important reviews are as follows: 
Kakwani and Pernia (2000) proposed an index to measure the degree of pro-poor index. This index is known as the pro-poor growth index (PPGI), and it is derived from the relation between total poverty reduction and poverty reduction in the case of distribution-neutral growth. In fact, this relation is expressed as the ratio of poverty elasticities, which will be higher than one when a growth scenario is pro-poor.

Besley et al (2007), in a paper entitled "Political Foundations of Poverty and Growth in India", highlighted the success and failure of various Indian states in achieving growth. In this study, two poverty headcount ratio indices including the inequality index (the standard deviation from the logarithms and income) and the logarithm of per capita income were calculated from 1958 through 2000 for the 16 states of India; then, fitting the regression model, they assessed the relationship between poverty and growth. The study concludes that states with a good level of accountability, proper environment for business investment, good access to finance and human capital, property rights for the poor, and with a good condition for the entry of women into the economic processes, had been able to act more successfully in the field of poverty reduction. Kakwani and Sun (2008), in a study entitled "Poverty equivalent growth rate," used data collected from 1955-2005 to calculate the poverty equivalent growth rate in Brazil. The results indicate that during the study period, the growth rate of per capita income in this country had been almost constant, and then the growth rate increased. Using the PEGR index, the distribution of the benefits of growth and the distribution of the losses of depression were examined based on the Foster, Greer, and Thorbecke indicators. The results indicate that Brazil's growth pattern in the first two years had not been in favor of the poor, but since then, it has benefited the poor from 1957 to 2005 .

Zaman (2016), in a study entitled "Poverty rate curve," presents a new indicator for measuring the pro-poverty growth rate. He believes that pro-poor growth is not well measured in very poor countries when using the indicators presented in the previous literature. Thus, in such countries, it is necessary to use the new index introduced in the mentioned study. In this index, the square of growth elasticity of poverty is used instead of the growth elasticity of poverty, and the square of inequality elasticity of poverty is used instead of inequality elasticity of poverty. This method has some benefits, as it reduces the effect of the sudden mutations in the growth rate and reflects the severity of inequality. He believes that using this method to calculate pro-poor growth in poor countries can provide more appropriate policy packages than those provided by previous indicators.

Raghfar et al. (1395), in a study entitled "The study of the relationship between economic growth and poverty and inequality in Iran," explored poverty's phenomenon during the first to 
fourth development plans. As a result, they calculated growth and inequality elasticity of poverty. They then assessed the distribution of the benefits of growth using the poverty equivalent growth rate index introduced by Kakwani and Sun (2008). This study showed that three out of every ten people were below the poverty line during the studied period. Indicators related to the poverty rate and poverty gap were very similar to those of the poverty headcount ratio. On average, poverty had been around $30 \%$ over the studied 30 years. The net effect of growth on poverty had been negative. Still, the net effect of inequality on poverty had positive and negative fluctuations, which were explained by the political and economic developments in Iran during the period under the study. Calculating poverty equivalent growth rate for Iran's first to fourth social and economic development plans, they concluded that, despite the existence of social and economic plans in the country, there had been no effective policy for achieving continuous welfare and prosperity. In other words, during the study period, there was no coherent plan to reduce poverty and inequality.

Abunouri and Ghader Abbasi (2007), in a study entitled "Estimating the effect of economic growth on poverty in Iran," separated the effect of economic growth on poverty into the two factors, including income and distributional factors and measured the impact of economic growth on poverty in Iran. In this study, the net effect of economic growth on poverty in Iran was estimated during several periods from 1982 to 1988 during the first development plan, from 1995 to 1999, during the second development plan, and from 2000 to 2002 during a part of the third development plan. For this purpose, they used the model developed by Kakwani, Khandeker, and Sun, a complementary model for the one proposed by Kakwani and Pernia (2000). Accordingly, using the effects of growth and net inequality, growth and net inequality elasticity of poverty were estimated by different poverty indicators; finally, the impact of growth on poverty was determined in the studied periods in different parts of urban and rural areas of Iran. The results of this study indicate that poverty increased during the period from 1981 to 1988 , and after the analysis of components of poverty it was found that the reduction in inequality had helped to reduce poverty caused by the economic depression, that is, the reduction of the share of high-income households was more than the reduction in the share of low-income households; although poverty had increased during this period, poor households were less harmed than the others. In other periods, poverty was reduced in urban areas; the decomposition of poverty in these periods shows that growth had led to a higher level of inequality in the distribution of income, but its rate had not been so much that the beneficial effect of growth would be completely neutralized. Growth in rural areas in the second and third periods had led to an unequal distribution of income. The level of inequality had increased to 
the degree that had completely neutralized the growth effect and resulted in an increase in poverty in the third period. In the fourth period, growth in rural areas was associated with a decrease in inequality. In sum, the results of the research indicate that during the first, second, and third-social and economic development plans, the small economic growth in Iran, except for the third plan, had not been a pro-poor growth. In other words, the increase in the share of high-income households had always been more than the increase in the share of low-income households. According to research findings, economic growth, on the one hand, reduces poverty, and on the other hand, makes changes in income inequality. Poverty has a reverse relationship with economic growth and a direct relationship with inequality. The increase in inequality has reduced the impact of economic growth on poverty. It can, therefore, be concluded that adopting hybrid policies, which result in growth and reduction in inequality, will be more effective in further reducing poverty and increasing the share of the poor in economic growth.

What distinguishes this study from previous studies is the examination of economic sectors in Iran, while considering the differences in relative advantages in each of the urban and rural areas. Each of the three sectors, including industry, service, and agriculture, were separately assessed divided by urban and rural areas, which have so far not been calculated and evaluated by any previous studies for Iran. To calculate poverty indicators and elasticity in each of these sectors, we designed a set of mathematical relationships between existing data and formulas, using mathematical tools and simple software such as Excel, all of which are explained in detail in Section 4.

\section{Theoretical Foundations}

The subjects of poverty and poverty reduction have always been a concern for nations, and this unbearable phenomenon, which is one of the main problems of human communities, has not been controlled yet; moreover, it has been constantly exacerbating with the expansion of human communities in various fields, including economics (Zarooki and Shahmiri Shormasti, 2012; 225).

Because of the need to deal with the poverty crisis, it should be examined and evaluated from theoretical and practical aspects. From a theoretical point of view, poverty and its components must be accurately identified and defined. From a practical point of view, it is necessary to measure the extent of poverty in the country or society under the study (Khodadadkashi et al., 2002; 9). 
Many researchers have studied poverty, and each has measured the impact of different factors on poverty that they believe it is more important than others are. The 2001 DAC guidelines on poverty reduction show that the forms of deprivation that poverty takes, economic, human, political, socio-cultural, protective (security) are interlinked, and the gender equity and environmental sustainability cut across all the dimensions of poverty. (Figure 1)

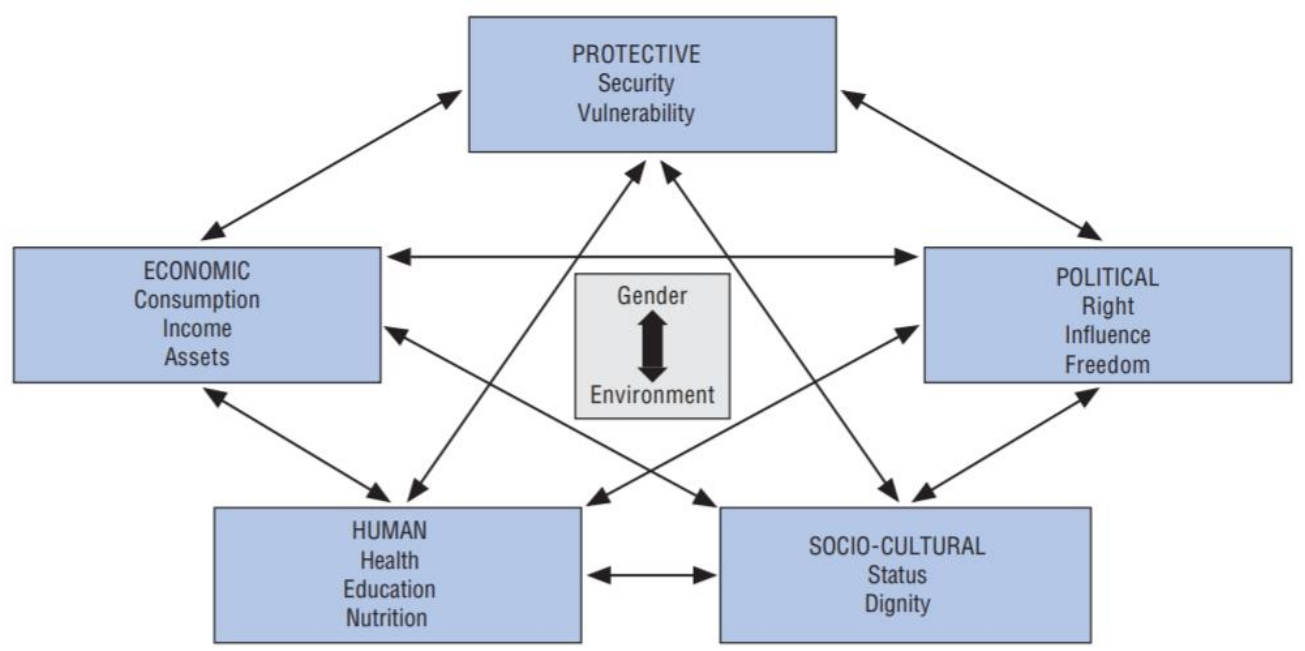

Figure 1. The multi-dimensional poverty framework

Source: Maning and Smith, 2007

Given the international commitment to eradicating poverty in developing countries, the relationship between economic growth, poverty reduction, and pro-poor growth has come into focus in recent years. There are different definitions for pro-poor growth. Based on a definition, pro-poor growth is a situation in which poor people benefit growth more than those who are not poor. Others have defined pro-poor growth as a growth that reduces poverty to an agreed level. This amount does not take into account the effect of growth on income distribution and, therefore, poverty. Therefore, to analyze the relationship between economic growth and poverty reduction, we need to consider the distributional effects. The distributional effects may change the overall process of growth, making it more or less than pro-poor growth.

Figure 2 presents the likely relationship between poverty, economic growth, and inequality. If $\mathrm{A}$ is the primary income curve, if economic growth is divided equally among all income categories of society, then B is the curve of the new income of the society, and the vertical distance between the two curves of $\mathrm{A}$ and $\mathrm{B}$ indicates the income growth for each income category in the society. Therefore, given equal income growth for all segments of society, income distribution will not change, and poverty levels will decrease from P0 to P1. 
Nevertheless, if income growth is not equally distributed between different income groups, the status of the income distribution will change. In such a condition, the status of poverty in society will be different. Curve $\mathrm{C}$ represents a situation in which the highest income classes are more benefiting from economic growth. In this case, although poverty has declined, this decline is less than the previous one. Besides, poverty increases among those who are lower than P3 (Jalilian and Patrick, 2005).

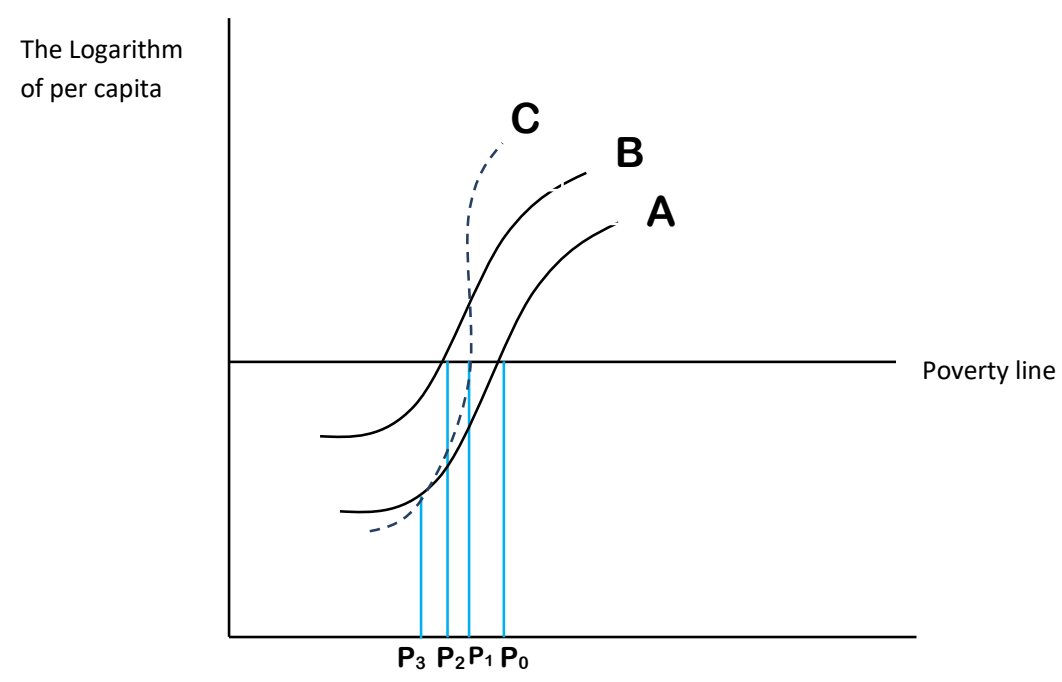

Figure 2 . The relationship between poverty, inequality and growth Source: Jalilian and Patrick, 2005

Deciding to fight poverty and allocating funds for poverty reduction is dependent on the index selected for measuring poverty and the method used for calculating the poverty line. Accordingly, understanding the types of poverty line and the characteristics of each of them are very influential in making decision and policies. After reaching an agreement over the concept and index of poverty, we must measure poverty using the relevant data. The following section presents the concept of poverty, poverty lines and their definitions, and poverty measurement indices.

For many years, economists have failed to define poverty based on standards acceptable for all, and there is still controversy among researchers. Booth and Rowntree, two of the pioneers of poverty studies in England in the late nineteenth century, tried to provide a proper definition of poverty. These two tried to distinguish between absolute poverty and relative poverty. Absolute poverty is an objective issue that requires a scientific definition based on minimum livelihood; it includes minimum items required to preserve life. Consequently, absolute poverty is defined as the inability to obtain the minimum standard of living. If a person is at a 
level below this minimum, he will not be able to continue living. Therefore, the definition of absolute poverty depends on how the minimum livelihood is defined. To do this, it is necessary to identify what people need, and how much goods and service are needed to alleviate their poverty. This conceptualization of absolute poverty, or the minimum livelihood, is in line with the Booth's last publications (1889) and the Rowntree (1901 and 1941).

Contrary to absolute poverty, relative poverty is a concept in which judgments are effective in determining the level of poverty. Relative poverty is defined as the failure to attain a certain level of living standards that are recognized as necessary or desirable in the current society. Relative poverty is due to severe income disparities, and it is not simply a result of the lack of resources for basic needs, but it emerges due to the lack of individual resources for accessing the minimum standard of living in the society. Therefore, in defining relative poverty, inequality in income distribution and wealth is more important than the absolute level of income of individuals. Development economists use the concept of absolute poverty to express a minimum amount of income to meet basic material needs, such as food, clothing, and housing, to ensure a permanent livelihood. Given that the minimum livelihood differs from country to country and from region to region, and as it represents different psychological, economic, and social needs, we face some problems with this definition (Todaro and Smith, 2009; 75). Therefore, in the present study, our definition of poverty is the relative poverty proposed by Booth and Rowntree.

The poverty line is defined as the level of expenses that a person must spend at a given time and place to reach a level of minimum welfare. People who do not have this level of welfare are considered poor. To measure poverty and define a person as a poor, we need to set a threshold that is called the poverty line (Ravallion, 1998; 133). In a simpler term, the poverty line is the amount of income that divides households at a given time and place into two parts, poor and non-poor (Harold, 1964; 16). Our benchmark for measuring the poverty line in this study is based on $50 \%$ or $66 \%$ of the average household expenditure. In this method, which is based on the concept of relative poverty, first, the average of expenditures is calculated. At a later stage, $50 \%$ or $66 \%$ of the average expenditures is considered as the poverty line (of course, determining this percentage is optional and empirical).

Because of the differences in the severity of poverty and the emergence of new needs in societies at various times, measuring the number and composition of the poor under the poverty line and its evolution over time is not enough; it is due to the differences in the distribution of income, the concepts of the poverty line, income, average expenditures of the poor, and the composition of the poor. Hence, when measuring poverty, we need some measures that would 
be sensitive to the mentioned items. FGT poverty indicators (Foster, Greer, and Thorbecke) include a group of poverty measures that, based on the size of the parameter $\alpha$, provide different indices of poverty that are suitable for measuring distributional and income effects on poverty. Using the mentioned indicators, the researchers can aggregate the levels of poverty obtained from studying different sub-populations and reach a single percentage of the total poverty in a population. Depending on the needs and different applications, the researchers can use the poor ratio indicators (which are more used to measure the number and ratio of the poor) the poverty gap index (which not only measures poverty, but also can measure the gap between the poor people in terms of their proximity to poverty line), and finally the poverty intensity index (which, in addition to the poverty gap, also takes into account the severity of the gap through weighting poorer groups). The general form of the Foster, Greer, and Thorbecke Function is as follows:

$P_{\alpha}=\int_{0}^{z}\left(\frac{z-x}{z}\right)^{\alpha} f(x) d x \quad, x \geq 0$ 1)

Where $f(x)$ is the density function, or in simpler terms, the ratio of the population with an income of $\mathrm{x}, \alpha$ is the distribution parameter, $\mathrm{z}$ is the poverty line, and $\mathrm{x}$ is the income. The larger the $\alpha$ the resulting index will be more sensitive to the income inequality in the poor (Foster et al., 1948; 670).

Watts's index: This indicator was defined by Watts in 1968, a logarithmic function of the poverty line to income ratio:

$\mathrm{W}=\int_{0}^{\mathrm{H}} \log \frac{\mathrm{z}}{\mathrm{x}}$

Where $\mathrm{z}$ is the poverty line, $\mathrm{q}$ is the number of the poor, $\mathrm{n}$ is the total population, and $\mathbf{x}_{\mathbf{i}}$ is the income of the individual i. Unlike Foster, Greer, and Thornback Function that presents a value between zero and one, this index is not necessarily smaller than one.

Various studies have been conducted on how poverty could be reduced in developing countries, and most of them have highlighted the economic growth as the main solution and approach to poverty reduction (Ravallion \& Chen, 2003; 5). However, inequality and its impact on economic growth have raised the question of whether the poor are always benefiting from economic growth? Although a group of economists believes that the poor automatically benefit from economic growth, many believe that economic growth alone is not enough to eliminate poverty: as they suggest, the method of distribution of the benefits of growth is also an important factor. Although poverty and inequality are two completely different phenomena, 
they are extremely interrelated. Inequality is of great importance to achieve poverty reduction goals because economic growth also indirectly affects poverty through the distribution of income. Hence, at a certain level of average income, higher levels of inequality lead to a higher level of poverty; in addition, at a certain level of economic growth, a higher level of inequality will decrease the poverty reduction rate (Lopez, 2005; 2).

There is much different inequality index, but because most inequality indicators are defined in terms of the ratio of the average or total income of the poor (lower income) to the average or total income of society, Therefore, high incomes are less considered in the mentioned inequality measures and the income gap between rich and poor people is not well reflected. In this regard, in 2007, Zanga introduced an index based on the ratio of the average income of lower-income people to higher-income people in society. This index, while having the necessary conditions for a good inequality index, better shows the relationship between poverty and wealth in society. Although the Gini coefficient is still the most common indicator of income inequality, it has many weaknesses and criticisms that it is not very reliable in showing how income is distributed (Mirzaee et al, 2019).

Zenga proposed a different approach to measuring and representing inequality. Observing the noticeable increase in disparities between less fortunate and more fortunate individuals, Zenga introduced a new inequality curve $I_{F}(p)$ obtained by contrasting the average income of the poorer $\mathrm{p} \%$ bottom earners $\frac{1}{p} \int_{0}^{p} F^{-1}(s) d s$ with the amount that is held, on average, by the richest top earners, i.e. the remaining (1-p)\% of the population, that is $\frac{1}{1-p} \int_{0}^{p} F^{-1}(s) d s$.

Therefore, he defined the curve $\left(\mathrm{p}, I_{F}(p)\right)$ where

$I_{F}(p)=\frac{\frac{1}{1-p} \int_{0}^{p} F^{-1}(s) d s-\frac{1}{p} \int_{0}^{p} F^{-1}(s) d s}{\frac{1}{1-p} \int_{0}^{p} F^{-1}(s) d s}, \quad$ for $0<p<1$

When the random variable $\mathrm{Z}$ is equal to a constant, the corresponding quantile $F^{-1}(p)$ is also equal to the constant and thus $I_{F}(p)=0$ for every $(0,1)$, meaning perfect equality or the "egalitarian society." The other extreme scenario is when, loosely speaking, there is only one member in the society who gets the entire income of the population and in this case $I_{F}(p)=1$ for every $(0,1)$.

As illustrated by Greselin et al. (2010), the methodology proposed by Zenga (2007) keeps "in mind that the notions of poor and rich are relative to each other" and summarizes, in a single 
measure, the amount of inequality in the population, by proposing the following summary index.

$I_{F}(p)=\int_{0}^{p} I_{F}(p) d p$.

In addition, the lessons learned from the most successful East Asian countries in the field of poverty reduction indicates that rapid growth, coupled with low initial inequality and a propoor shift in distributions, can significantly reduce poverty, because income inequalities affect the speed of poverty reduction realized through economic growth, so can said how is inequality important. Sometimes it may even prevent poverty reduction or also increases poverty. However, when the benefits of growth for the poor are more than that for the rich, poverty can decline further. In other words, economic growth can further alleviate poverty by reducing inequality. In fact, in the event of a reduction in inequality (compared with time without a change in inequality), economic growth can result in a higher level of poverty reduction. Therefore, the change in inequality can result in a meaningful change in poverty; moreover, primary inequality in assets is unfavorable for the poor and contributes to an increase in poverty. Thus, low initial inequality increases the chances for the poor to benefit from economic growth (Bigsten and Levin, 2000).

The figure 3 shows the poverty-inequality-growth triangle (sometimes called the growth inequality-poverty triangle (Dhrifi, 2015)) was first used by Bourguignon (2004) to describe the fact that a country's change in absolute poverty can be fully determined by its change in income growth and income inequality (McKnight,2019).

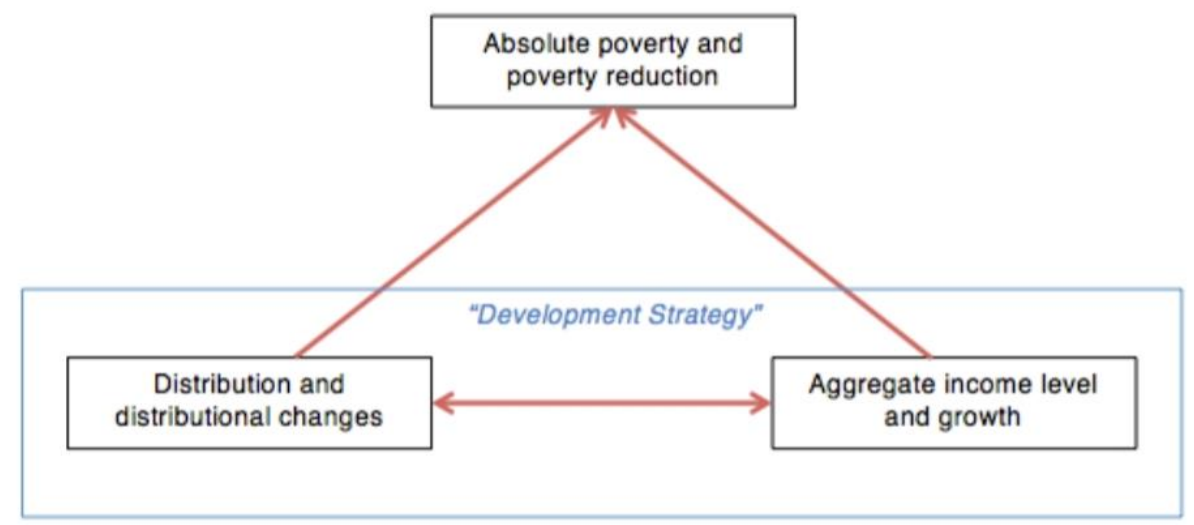

Figure 3. The poverty- inequality- growth triangle

Source: Bourguinon, 2004

To find out the effects of economic growth on poverty, it is necessary to separate and discriminate the effects of economic growth on income and income inequality; hence, it is 
essential to divide the changes in the poverty indicator into two components including the changes in the average income and the changes in income inequality. Changes in these components indicate the sensitivity of poverty levels to changes in average income and income inequality. Therefore, we can examine the effect of economic growth on poverty from these two channels: direct effect or the effect of income, and indirect effect or the distributional effect that is realized through changes in income distribution.

One of the most prominent ways of determining the pro-poor growth is the use of pro-poor growth indices, including PPGI and PEGR. PPGI index shows the potential power of economic growth in reducing poverty, and it is independent of growth rate; taking into account the ratio of growth elasticity of poverty in general, and the growth elasticity of poverty at a constant distribution, it shows that how changes in income distribution affects poverty during the time of growth. On the other hand, PEGR index shows how the status of poor changes during the depression or boom. In a society where the income status of all people has worsened and the income of non-poor income has decreased more than the income of the poor, the PEGR may indicate a higher level of pro-poor growth than in a society where the income of all income groups is increased. Moreover, PEGR index may indicate a pro-poor growth in a society where only the income of the poor is increased, even if this improvement in the status of poor people is due to the redistribution of income during the time of depression. Thus, in this study, PPGI was used as the criterion for measuring the pro-poor growth.

\section{Research Method}

Considering the theoretical and empirical foundations, each poverty index can be considered a function of various parameters such as the poverty line, average per capita income, and distribution index. It is evident that the change in each of these parameters will lead to a change in the desired index. In this estimate, if $\theta$ is the desired poverty index:

$\theta=\mathrm{f}\left(\mathrm{z}, \mu_{\mathrm{i}}, \mathrm{m}\right)$

Where $\mathrm{z}$ represents the poverty line, $\mu \mathrm{i}$ is the average income of the desired province, and $\mathrm{m}$ is the parameter of inequality.

The changes in these indicators are generally defined as follows:

$\mathrm{d} \theta=\frac{\partial \theta}{\partial \mu} \mathrm{d} \mu+\frac{\partial \theta}{\partial \mathrm{m}} \mathrm{dm}$

Given that each index has its drawbacks and benefits, to settle down the drawbacks and increase the precision, we measure poverty using the four indicators as follows: 
If $\mathrm{q}$ is the number of poor people and $\mathrm{n}$ is the total population of society, then the indicator of the ratio of poor people is estimated as follows:

$\mathrm{H}=\frac{\mathrm{q}}{\mathrm{n}}$

In order to calculate the index of income gap ratio in the studied society, we use the following equation:

$P G=\frac{1}{n} \sum_{i=1}^{q}\left(\frac{z-x_{i}}{z}\right)$

The following equation is used to calculate the square income gap index in the target population:

$\mathrm{SPG}=\frac{1}{\mathrm{n}} \sum_{\mathrm{i}=1}^{\mathrm{q}}\left(\frac{\mathrm{z}-\mathrm{x}_{\mathrm{i}}}{\mathrm{z}}\right)^{2}$

The following equation is used to calculate Watts index in society:

$\mathrm{W}=\sum_{i=1}^{q} \log \left(\frac{\mathrm{z}}{\mathrm{x}_{\mathrm{i}}}\right)$

If we show the general poverty index as follows:

$\theta=\theta(\mathrm{z}, \mu, \mathrm{L}(\mathrm{P}))$

Where $\mathrm{z}$ is the poverty line, $\mu$ is the average income, and $\mathrm{L}(\mathrm{P})$ is the Lorenz curve.

When the distribution of income in the first year is equal to an average income of $\mu_{1}$ and a Loren curve of $\mathrm{L} 1(\mathrm{P})$ and the distribution of income in the last year is equal to an average income of $\mu_{2}$ and a Lorenz curve of L2(P), then P12 represents the change in poverty between the two periods, which is calculated as follows:

$\mathrm{P}_{12}=\ln \left[\theta\left(\mathrm{z}, \mu_{2}, \mathrm{~L}_{2}(\mathrm{P})\right)\right]-\left[\theta\left(\mathrm{z}, \mu_{1}, \mathrm{~L}_{1}(\mathrm{P})\right)\right]$

Given the changes in poverty between the two periods, the total elasticity of poverty can be estimated as follows:

$\delta=\frac{\ln \left[\theta\left(\mathrm{z}, \mu_{2}, \mathrm{~L}_{2}(\mathrm{P})\right)\right]-\left[\theta\left(\mathrm{z}, \mu_{1}, \mathrm{~L}_{1}(\mathrm{P})\right)\right]}{\gamma}$

Where $\gamma$ represents the average growth rate of income and is calculated as follows:

$\gamma=\ln \left(\mu_{2}\right)-\ln \left(\mu_{1}\right)$

Based on Kakowani's poverty decomposition method (2000), we can divide the total growth elasticity of poverty into income elasticity and distributional elasticity, the sum of which is equal to the total elasticity:

$\delta=\rho+\varphi$

Where $\rho$ is the income elasticity, and $\varphi$ is the distributional elasticity. In the following section, we will discuss each of these two. 
The ratio of the change in poverty between the two periods, when the average income changes but the relative distribution of income remains constant, represents the effect of net growth calculated by the following equation:

$G_{12}=\frac{1}{2}\left[\ln \left(\theta\left(\mathrm{z}, \mu_{2}, \mathrm{~L}_{1}(\mathrm{P})\right)-\ln \left(\theta\left(\mathrm{z}, \mu_{1}, \mathrm{~L}_{1}(\mathrm{P})\right)+\ln \left(\theta\left(\mathrm{z}, \mu_{2}, \mathrm{~L}_{2}(\mathrm{P})\right)-\ln \left(\theta\left(\mathrm{z}, \mu_{1}, \mathrm{~L}_{2}(\mathrm{P})\right)\right]\right.\right.\right.\right.$

We can obtain income elasticity using the effect of net growth, similar to the total elasticity of poverty relative to growth, as follows:

$\rho=\frac{\frac{1}{2}\left[\ln \left(\theta\left(\mathrm{z}, \mu_{2}, \mathrm{~L}_{1}(\mathrm{P})\right)-\ln \left(\theta\left(\mathrm{z}, \mu_{1}, \mathrm{~L}_{1}(\mathrm{P})\right)+\ln \left(\theta\left(\mathrm{z}, \mu_{2}, \mathrm{~L}_{2}(\mathrm{P})\right)-\ln \left(\theta\left(\mathrm{z}, \mu_{1}, \mathrm{~L}_{2}(\mathrm{P})\right)\right]\right.\right.\right.\right.}{\gamma}$

Income elasticity is the amount of change in poverty caused by a unit of change in the average income when the relative distribution of income measured by the Lorenz curve is constant. Based on Kakowani's study, this elasticity is always negative, since, with the constant distribution of income, positive growth always reduces poverty.

The effect of net inequality is the ratio of change in poverty when the distribution of income changes, but the average income remains constant, which is calculated as follows:

$\mathrm{I}_{12}=\frac{1}{2}\left[\ln \left(\theta\left(\mathrm{z}, \mu_{1}, \mathrm{~L}_{2}(\mathrm{P})\right)-\ln \left(\theta\left(\mathrm{z}, \mu_{1}, \mathrm{~L}_{1}(\mathrm{P})\right)+\ln \left(\theta\left(\mathrm{z}, \mu_{2}, \mathrm{~L}_{2}(\mathrm{P})\right)-\ln \left(\theta\left(\mathrm{z}, \mu_{1}, \mathrm{~L}_{1}(\mathrm{P})\right)\right]\right.\right.\right.\right.$

By obtaining the net distributional effect, we will be able to calculate poverty's distributional elasticity using the following equation:

$\varphi=\frac{\frac{1}{2}\left[\ln \left(\theta\left(\mathrm{z}, \mu_{1}, \mathrm{~L}_{2}(\mathrm{P})\right)-\ln \left(\theta\left(\mathrm{z}, \mu_{1}, \mathrm{~L}_{1}(\mathrm{P})\right)+\ln \left(\theta\left(\mathrm{z}, \mu_{2}, \mathrm{~L}_{2}(\mathrm{P})\right)-\ln \left(\theta\left(\mathrm{z}, \mu_{1}, \mathrm{~L}_{1}(\mathrm{P})\right)\right]\right.\right.\right.\right.}{\gamma}$

The distributional elasticity of poverty is the effect of economic growth on poverty caused by a unit of change in the relative distribution of income when the average income is constant. The sign of this type of elasticity can be either positive or negative.

Using distributional and income elasticity, we can calculate poverty equivalent growth rate (PEGR), which is one of the most important ways of determining pro-poor growth. The growth rate $\gamma^{*}$ will result in the same level of poverty reduction as the present growth rate $\gamma$ if the growth process had not been accompanied by any change in inequality (when everyone in the society had received the same proportional benefits of growth). The actual proportional rate of poverty reduction is given by $\delta \gamma$, where $\delta$ is the total poverty elasticity. If the growth were distribution neutral (when inequality had not changed), then the growth rate $\gamma^{*}$ would achieve a proportional reduction in poverty equal to $\rho \gamma^{*}$, which should be equal to $\delta \gamma$. Thus, the PEGR denoted by $\gamma^{*}$ will be given by

$\gamma^{*}=\frac{\delta}{\rho} \gamma=\varphi \gamma$ 
It should be noted that in order to obtain the poverty indices and total elasticity, income elasticity, and distributional elasticity relative to economic growth, in addition to calculating the poverty level at the beginning of the period $\theta\left(\mathrm{z}, \mu_{1}, \mathrm{~L}_{1}(\mathrm{P})\right)$ and the end of the period $\theta\left(\mathrm{z}, \mu_{2}, \mathrm{~L}_{2}(\mathrm{P})\right)$ it is necessary to calculate two abstract values including $\theta\left(\mathrm{z}, \mu_{1}, \mathrm{~L}_{2}(\mathrm{P})\right)$ and $\theta\left(\mathrm{z}, \mu_{2}, \mathrm{~L}_{1}(\mathrm{P})\right)$. To calculate the formula for the function $\theta$, we must first obtain the values of $\mu, \mathrm{L}(\mathrm{P})$, and then extract the general formula of the function $\theta$. Accordingly, in addition to two actual levels of poverty at the beginning and end of the period, two abstract values will be calculated as well, which makes it more difficult and increases likely errors and requires the use of specialized software such as Povcalnet. Therefore, this study used the following option: If $X_{1}=\left[x_{1}, x_{2}, \ldots, x_{n}\right]$ is the income curve at the beginning of the period and $X_{2}=$ $\left[x_{1}, x_{2}, \ldots, x_{n}\right]$ is the income curve at the end of the period, then;

Poverty at the beginning of the period:

$f\left(z, x_{1}\right)=\theta\left(\mathrm{z}, \mu\left(\mathrm{x}_{1}\right), \mathrm{L}\left(x_{1}\right)\right)$

Poverty at the end of the period:

$f\left(z, x_{2}\right)=\theta\left(\mathrm{z}, \mu\left(\mathrm{x}_{2}\right), \mathrm{L}\left(x_{2}\right)\right)$

In addition, the two abstract values are also determined as follows:

Poverty in a situation where only the distribution of incomes changes, but average income remains constant:

$f\left(z, x_{12}\right)=\theta\left(\mathrm{z}, \mu\left(\mathrm{x}_{1}\right), \mathrm{L}\left(x_{2}\right)\right)$

Poverty in a situation where only average income changes, but the distribution of incomes remains constant:

$$
f\left(z, x_{21}\right)=\theta\left(\mathrm{z}, \mu\left(\mathrm{x}_{2}\right), \mathrm{L}\left(x_{1}\right)\right)
$$

Now, without the need for the formula of the function $\theta$, using the general functions of poverty $f(z, x)$ where the values of the curves of $x_{1}, x_{2}, x_{12}$, and $x_{21}$ are known, we can calculate all the actual and abstract values of poverty needed to calculate indices and elasticity.

$$
\begin{aligned}
& x_{12}=f^{-1} \theta\left(\mathrm{z}, \mu\left(\mathrm{x}_{1}\right), \mathrm{L}\left(x_{2}\right)\right) \\
& x_{21}=f^{-1} \theta\left(\mathrm{z}, \mu\left(\mathrm{x}_{2}\right), \mathrm{L}\left(x_{1}\right)\right)
\end{aligned}
$$

And for estimate Zenga index on real data, suppose that there are $\mathrm{n}$ households in a real sample, and let $z_{1}, \ldots, z_{n}$ be the observed ranked values of a quantitative variable $\mathrm{Z}$ (say gross income, tax or net income). 
We have seen that the Zenga index compares the average of the attribute at stake from the first household to the $\mathrm{i}$-th one, say $M_{i}^{-}(Z)=\frac{1}{i} \sum_{j=1}^{i} z_{j}$ with the average of the remaining $\mathrm{n}-\mathrm{i}$ households $M_{i}^{+}(Z)=\frac{1}{n-i} \sum_{j=i+1}^{i} z_{j}$. Therefore, the ratio

$I_{i}(Z)=\frac{M_{i}^{+}(Z)-M_{i}^{-}(Z)}{M_{i}^{+}(Z)}$,

describes the inequality at each percentile of the distribution. If all income earners hold the same income, all ratios are equal; conversely their variability is a direct function of inequality. We will consider also the complementary curve $U_{i}(Z)$, called the uniformity curve, defined by $U_{i}(Z)=1-I_{i}(Z)=\frac{M_{i}^{-}(Z)}{M_{i}^{+}(Z)}$,

Which has the advantage of a more straightforward interpretation, since it simply measures $M_{i}^{-}(Z)$ in terms of a percentage of $M_{i}^{+}(Z)$. Both $U_{i}(Z)$ and $I_{i}(Z)$ potentially range between 0 and 1 (Zenga, 2007), and are not constrained in their end points, for $i=1 / n$ and $i=(n-$

$1) / \mathrm{n}$, differently $L_{i}(Z)=\frac{\sum_{j=1}^{i} z_{j}}{\sum_{j=1}^{n} z_{j}}$, that always begins in $(0,0)$ and ends in $(1,1)$. Moreover, $I_{i}(Z)$ and $U_{i}(Z)$ can be expressed in terms of $L_{i}(Z)$ (Zenga, 2007):

$I_{i}(Z)=\frac{1-p_{i}}{p_{i}} \frac{L_{i}(Z)}{1-L_{i}(Z)}$

$U_{i}(Z)=1-\frac{1-p_{i}}{p_{i}} \frac{L_{i}(Z)}{1-L_{i}(Z)}$

Finally, we arrive at the empirical estimators $\hat{I}(Z)$ of the Zenga index (Greselin et al., 2010):

$\hat{I}(Z)=\frac{1}{n-i} \sum_{i=1}^{n-1} \frac{\frac{1}{n-i} \sum_{j=i+1}^{n} z_{j}-\frac{1}{i} \sum_{j=1}^{i} z_{j}}{\frac{1}{n-i} \sum_{j=i+1}^{n} z_{j}}$.

\section{Data and results}

The data used in this study included the household budget data covering the period from 2005 to 2018. In fact, household budget is one of the most fundamental statistical data assessed in most countries of the world to achieve various economic and social goals. Through the assessment of this data, one can evaluate household expenses and incomes and their changes, obtain various statistics and information that help identify household patterns and habits and examine their trends and changes due to economic and social factors. Also, they help determine the share of different costs in the total expenditures of a household and the consumption pattern of different classes of society; such a data also helps to decide on the provision of relative welfare and livelihoods and provides plenty of other information. However, we used this data because they make it possible to calculate various poverty and income distribution indicators, 
which are available in household budget data. Therefore, in this study, household budget data were used to assess society under the survey. Because of the large size of the target population, ten provinces were selected for the study.

\section{5-1. Results}

As presented in Table 1, the poverty equivalent growth rates are overall higher than the actual growth rates in Iran during the period. For example, the PEGR was -0.06 per cent in industry sector in urban area, whereas the annual growth rate was actually only -0.2 per cent in that same sector. What does this imply? It suggests that, the poor benefited proportionally much more than the non-poor. Nevertheless, when the actual growth is negative. It means poor bother less than non-poor.

Table 1. The poverty equivalent growth rates

\begin{tabular}{|c|c|c|c|c|c|c|}
\hline & \multicolumn{3}{|c|}{ Urban area } & \multicolumn{3}{|c|}{ Rural area } \\
\hline sectors & $\begin{array}{c}\text { Industry } \\
\text { sector }\end{array}$ & $\begin{array}{c}\text { Services } \\
\text { sector }\end{array}$ & $\begin{array}{c}\text { Agriculture } \\
\text { sector }\end{array}$ & $\begin{array}{c}\text { Industry } \\
\text { sector }\end{array}$ & $\begin{array}{c}\text { Services } \\
\text { sector }\end{array}$ & $\begin{array}{c}\text { Agriculture } \\
\text { sector }\end{array}$ \\
\hline distribution effect & -0.09241 & -0.04769 & -0.07188 & -0.07309 & -0.08264 & -0.05194 \\
\hline income effect & 0.131414 & 0.054322 & 0.086603 & 0.152569 & 0.064598 & 0.107851 \\
\hline total effect & 0.039 & 0.006628 & 0.014723 & 0.079482 & -0.01804 & 0.055911 \\
\hline household income growth & -0.20699 & -0.12875 & -0.14887 & -0.26793 & -0.17272 & -0.21767 \\
\hline PEGR & -0.06143 & -0.01571 & -0.02531 & -0.13958 & 0.048244 & -0.11284 \\
\hline Poverty at the beginning of the period & 0.29419 & 0.156478 & 0.271069 & 0.189287 & 0.149478 & 0.156726 \\
\hline $\begin{array}{l}\text { Poverty at the end of the period } \\
\text { average of household income at the }\end{array}$ & 0.333189 & 0.163106 & 0.285792 & 0.26877 & 0.131434 & 0.212638 \\
\hline $\begin{array}{l}\text { beginning of the period } \\
\text { average of household income at the }\end{array}$ & 12988956 & 16999923 & 12770268 & 7944044 & 9519735 & 8515110 \\
\hline end of the period & 10300380 & 14811192 & 10869209 & 5815592 & 7875488 & 6661656 \\
\hline
\end{tabular}

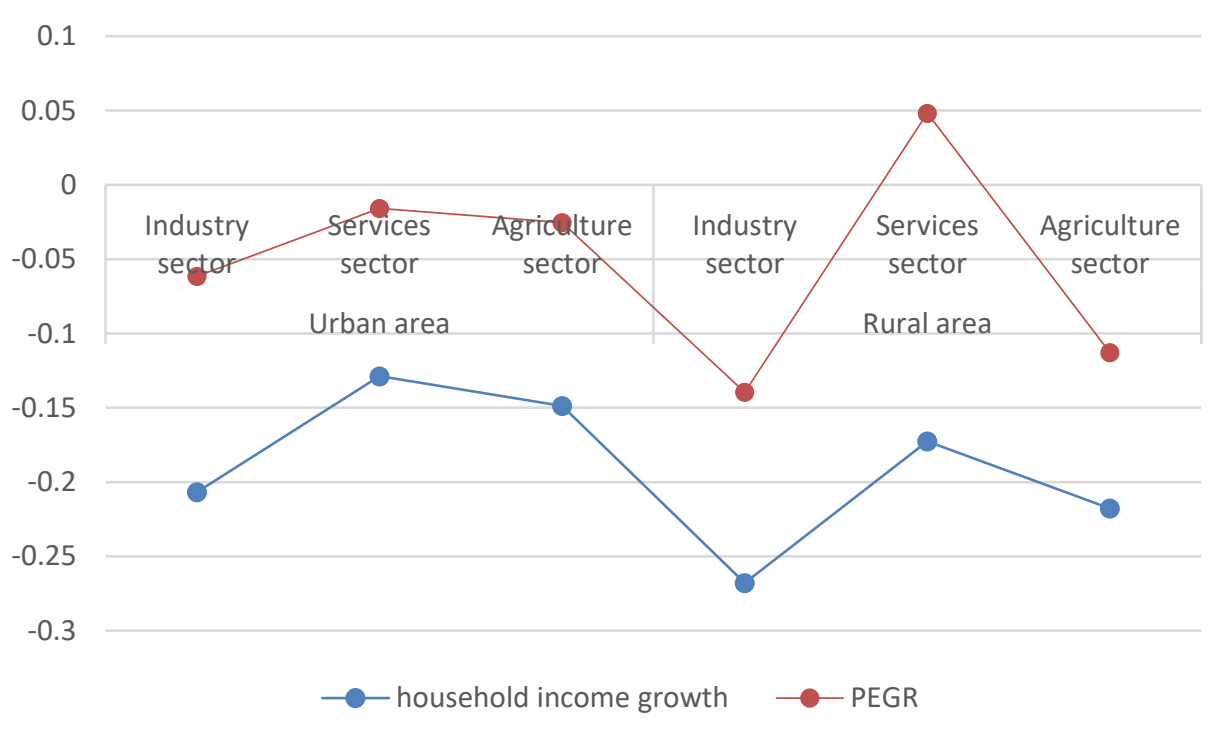

Figure 4. The poverty equivalent growth rates by sectors 
So as shown in the figure 4, PEGRs is higher than actual growth rates the in all of the sectors. This indicates that the deflation had adverse impacts on the non-poor more than on the poor.

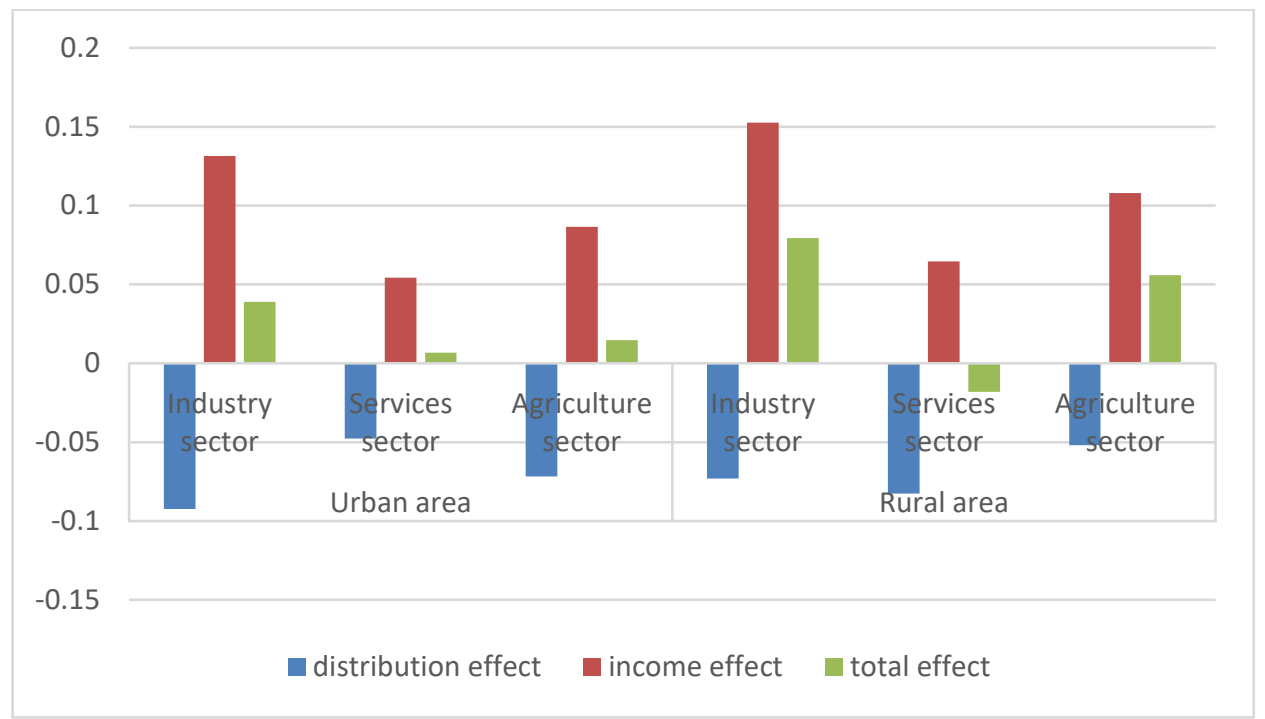

Figure 5. The poverty equivalent growth rates by sectors

The results show that the distributional effect in all sectors had reduced poverty and inequality of income. That means that the distribution of income had served the poor. Although income effect have increased poverty, the distribution of income had led poor people to suffer less damage from poverty.

Considering that the distributional effect has reduced poverty and income effect has increased poverty .Therefore, we are faced with two situations $0>\gamma^{*}>\gamma$ and $\gamma^{*}>0>\gamma$. In all sectoes, we are facing the first situation, except for the rural service sector. It means in this sector distribution effect not only neutralizes all the destructive effects of income Effect, but ultimately reduces poverty.

In the rural service sector, poverty reduction was observed, and the growth is pro-poor. There was no positive growth in any of the sectors, but it can be said that the urban service sector had the minimum contribution to poverty, and thus it was the best sector after the rural service sector.

Elsewhere, improved income distribution has offset only part of the negative effects of the recession on poverty, and the situation of the poor has worsened. Still, they have suffered less than the non-poor.

Table 2. Estimation of Zenga index by sectors

\begin{tabular}{c|c||c}
\hline & Urban area & Rural area \\
\hline \hline
\end{tabular}




\begin{tabular}{c|ccc||ccc}
\hline \hline sectors & $\begin{array}{c}\text { Industry } \\
\text { sector }\end{array}$ & $\begin{array}{c}\text { Services } \\
\text { sector }\end{array}$ & $\begin{array}{c}\text { Agriculture } \\
\text { sector }\end{array}$ & $\begin{array}{c}\text { Industry } \\
\text { sector }\end{array}$ & $\begin{array}{c}\text { Services } \\
\text { sector }\end{array}$ & $\begin{array}{c}\text { Agriculture } \\
\text { sector }\end{array}$ \\
\hline \hline $\begin{array}{c}\text { at the beginning of } \\
\text { the period }\end{array}$ & 0.81976 & 0.816512 & 0.80437 & 0.808916 & 0.821719 & 0.806964 \\
$\begin{array}{c}\text { at the end of the } \\
\text { period }\end{array}$ & 0.785901 & 0.796516 & 0.779419 & 0.778581 & 0.782112 & 0.782079 \\
\hline
\end{tabular}

As shown in Table 2, the Zanga index results indicate that inequality has decreased in all sectors during the period under review. Also, these results confirm the results obtained using the distribution effect. According to the Zanga index results, the rural service sector was the best sector in reducing income distribution inequality.

\section{Conclusions and recommendations}

Poverty is now one of the most important challenges of human life; eliminating this social problem is one of the most important goals to achieve through economic growth and development. Comprehensive growth has a crucial role in accelerating poverty reduction. However, inequality affects the way the poor benefit from growth. Over the past decades, countries that have paid attention to the two economic growth issues and the improvement in income distribution have been able to take effective steps to reduce poverty. Economic growth alone cannot reduce poverty. In the process of economic growth, the increase in household income leads to a reduction in poverty. However, the distribution of income among households must be organized in a way that the poorer households benefit more from the growth. As was mentioned, economic growth influences poverty and makes its effect through two channels, i.e., growth of average income and distribution of income. Hence, in this study, the effects of both income distribution and average income growth on poverty were analyzed.

As stated above, the aggregated effects of the two distributional and income effects will determine the changes in poverty and the subsequent growth. Therefore, distributional and income effects were calculated. As the main goal of this study was to estimate pro-poor growth index, we estimated distributional and income elasticity effects to calculate PEGR and determine whether the growth was pro-poor or not. Income and distributional effects were calculated for all the sectors by urban and rural areas. The results show that the distributional effect in all cases had reduced poverty and inequality of income. This means that the distribution of income had served the poor and led poor people to suffer less damage from poverty. The history of politics in Iran over the past decades also shows that the redistribution of wealth is the most important function of economic policy. The study of recent developments suggests that this feature has intensified over the past recent years. The review of general 
orientations of economic policies shows that the economic policy has largely been geared towards a kind of redistribution of wealth in society. Examining the major macroeconomic policy areas properly proves this idea. Therefore, as government functions in the economy can be formulated in the form of two policies of economic growth or accumulation and redistribution policies, during the studied period, the economic policies have been largely directed toward the second aspect. For instance, policies such as the Mehr Housing, Equity Stocks, and the targeting of subsidies are clearly representing significant redistribution features. From the theoretical point of view, the main goal of these policies is to reduce the economic gap even in a situation where growth is undermined.

The results show that the rural service sector had the highest PEGR value and was the dominant sector, contributing to pro-poor growth. Therefore, the rural service sector was the first to reduce poverty, as it had the best results in the decade under the study. Generally, although there was a negative growth in all the sectors, the service sector in rural areas with the highest PEGR value had the best performance during this period. Negative growth had a detrimental income effect on poverty, as the decreased income level resulted in a rise in poverty and exacerbated the conditions for poor. However, it can be said that the distributional effect improved the distribution of income and reduced inequality for the poor and consequently reduced poverty. It not only neutralized all the effects of income on poverty, but also ultimately reduced poverty significantly. However, in the other sectors, although the effects of distribution reduced poverty, the effects of income, increased poverty, and total poverty increased. However, improving income distribution has eliminated some of the increase in poverty. The result of the Zenga index shows that inequality in all sectors was reduced during that period.

Therefore, it can be said that rural areas have been more effective in reducing poverty, which can be attributed to the fact that, with the acceleration of the industrialization process, Iran was facing the challenges of growing inequality in urban and rural areas, the explosion of population in large cities, and the emergence of deserted villages where physical and human capital are lost. Therefore, the government tried to accelerate rural development by applying different policies and change this unfavorable situation. Since the reduction in poverty and income inequality can be achieved through increasing the income levels of poor farmers, policymakers have concentrated on raising the level of literacy, providing modern manufacturing inputs and technology, and expanding the economic infrastructure network, including roads, water, electricity, and telecommunication facilities. The government provided these services in rural areas. Therefore, the government's efforts to increase agricultural 
production and achieve self-reliance on agricultural products intensified. Accordingly, the government started implementing programs such as low-interest loans for investment in agriculture and agro-industrial complexes, provided production inputs, bank facilities for irrigation networks, and tax exemptions for farmers, focused on the rapid expansion of the road network, electricity, and telecommunications in remote rural areas, developed insurance schemes for strategic agricultural products, and developed rural clinics. In addition, although agriculture is traditionally defined as the axis of rural development, and the village is known for its agricultural and livestock activities, the development of agricultural activities is reliant on natural resources and natural resource constraints in some villages have led to economic decline; thus, the development in the agricultural sector did not result in the economic growth in all communities.

As a consequence, the rural sector is not limited to agriculture and livestock anymore. Villages are now a suitable environment for the growth of non-agricultural sectors and a place for the activities of manufacturing and service companies if they are competitive and resource-based. This is in fact, a kind of move from a natural resource-based business to a knowledge-based business. In most Americas, European, and even Asian countries, such as China, Malaysia, etc. the policy of entrepreneurship development in non-agricultural areas has been implemented in the villages.

With the development of entrepreneurship and the creation of small entrepreneurial firms and an increase in employment and production, villagers will achieve their goods and services, which will have a major impact on rural economic growth and reduce the phenomenon of migration to cities. The condition of the rural society in Iran shows that, with increasing the level of literacy and improving the scientific and practical knowledge and skills, the tendency towards employment in traditional sectors of the economy is reduced, and the desire for employment in modern and service sectors is promoted. As a result, the highest level of poverty reduction in the service sector was observed in the rural areas of the provinces under the study. As the results show, during the period under the study, the growth was negative in all cases, so the average income has increased poverty. Accordingly, the few cases of poverty reduction were generally due to a change in the distribution of income. However, the goal is not to reduce poverty alone, but it is also aimed to reach pro-poor growth. Therefore, it is recommended to take into account the damages of negative growth during the study period on poor people and the general welfare of the society, and simultaneously pay attention to the growth and reduction of poverty, and direct economic policies toward increasing the rate of growth. 
Declaration

Availability of data and materials:

On the request are available

Competing interests:

N/A

Funding:

No

Authors' contributions

Mohammad Sharif Karimi: Contributed data or analysis tools and Conceived and designed the analysis, Sohrab Delangizan: Performed the analysis, Elham Heshmati daiari: Collected the data.

Acknowledgements

No

Authors' information (optional)

N/A

\section{References}

1. Abonori, E, Abbasi Ghaderi, R. (2007). "Estimating the Effect of Economic Growth on Poverty in Iran", Iranian Quarterly Journal of Economic Research, No. 30.

2. Ahluwalia, M.S. (1976). "Inequality, Poverty and Development" Journal of Development Economics, Vol. 3(4): 307-42.

3. Arzrom Chiller, N. (2005). "Various Dimensions of Poverty in Iran". The Series of Economic Research, Central Bank of the Islamic Republic of Iran, No. 27.

4. Besley, T. R. Burgess and Esteve-Volart, B. (2004). "Operationalizing Pro-Poor Growth: A Case Study on India", Prepared as part of the Operationalizing Pro-Poor Growth research program. Processed. World Bank, Washington, DC.

5. Bigsten, A., and Levin, J. (2000). "Growth, Income Distribution and Poverty A Review", Department of Economic Goteborg University, Working Paper in Economics, No 32.

6. Bozeli, T., and Luiz, K. (2010). "Pro-poor growth", translated by Shakeri, Abbas. and Maleki, Amin. Nai Publication.

7. Chenery, H., and Ahluwhalia, M. (1974). Redistribution with Growth. Oxford: Oxford University Press.

8. Foster, J., Joel, G., and Erik, T. (1984), "Notes and Comments A Class Of Decomposable Poverty Measures"', Econometrica, vol, 52, No, 3. 
9. Jalilian, H., and Kirkpatrick, C. (2005). "Does Financial Development Contribute to Poverty Reduction?”. Journal of Development Studies, Vol. 41, May 2005, PP 636656.

10. Kakwani, N. (2000) "On Measuring Growth and Inequality Components of Poverty with application to Thailand", Journal of Quantitative Economics.

11. Kakwani, N., and Son, H. (2008). "Poverty Equivalent Growth Rate", Review of Income and Wealth 54(4).

12. Kakwani, N., and Pernia, E. (2000). "What is Pro-poor Growth", Asian Development Review, Vol. 16, No.1, 1-22.

13. Kakwani, N., and Son, H. (2008). "Poverty Equivalent Growth Rate", Review of Income and Wealth 54(4).

14. Kakwani, N., Khandker, S.. and Son, H.H.(2004). "Pro-poor Growth: Concepts and Measurements with Country Case Studies", UNDP International Poverty Center, Working Paper, 1.

15. Khalid, Z. (2016). "Poverty Intensive Curve: A new form Of Pro-Poor Index", Forensic research and criminology International Journal.

16. Khodadadkashi, F. (2002). "Measuring Poverty Indicators in Iran," Research Institute of Statistical Centre of Iran.

17. Klump, R. (2007). "Was Growth Pro-Poor in Vietnam? Assessments and policy Recommendations". Deutsche Gesellschaft fur Technische zusammenarbiet, Eschborn, Germany.

18. Kravis, I.B. (1960). "International Differences in the Distribution of Income" Review of Economics and Statistics, Vol. 42: 408-16

19. Kuznets, S. (1955). "Economic Growth and Income Inequality", American Economic Review, Vol. 45, 1-28.

20. Lopez, H .(2005a)."Growth and Inequality: Are they connected" Working Paper, World Bank, Washington, Dc.

21. Lopez, H. (2005b)."Pro-Poor Growth: How Important Is Macroeconomic Stability?" Working Paper, World Bank, Washington, Dc.

22. Oshima, H. (1962). "International comparison of size distribution of family incomes with special reference to Asia" Review of Economics and Statistics, Vol. 44: 439-45

23. Paolo, V. (2006). "Pro-poor Growth during Exceptional Growth. Evidence from a Transition Economy" The European Journal of Comparative Economics Vol. 3, n. 1, pp. 3-14.

24. Paukert, F. (1973). "Income Distribution at different levels of development: a survey of evidence" International Labour Review, Vol. 108(2): 97-125.

25. Raghfar, H., Babapour, M., and Yazdanpanah, M. (2016). "The Study of the Relationship between Economic Growth and Poverty and Inequality in Iran during the First to Fourth Development Plans", Journal of Applied Economic Studies, Vol. 4, No. 16, PP. 59-79.

26. Ram, R. (1988). "Economic development and income inequality: further evidence on the U-curve hypothesis" World Development, Vol. 16(11): 1371-1376.

27. Ravallion, M., and Chen, S. (2003). "Measuring pro-poor growth". Economic Letters, Vol.78, No.1, PP.93-99.

28. Ravallion, M. (1997). "Can High-Inequality Developing Countries Escape Absolute Poverty?" Economics Letters 56: 51-57. 
29. Richard, H., and Adams, j. (2002). "Econimic Growth, Inequality and poverty: Finding from a new Data set", World Bank, Working Paper 2972.

30. Sandip, S. (2014). "Pro poor Growth:a Partial Ordering Opproach" Economic Research Unit, Indian Statistical Institute.

31. Soheyla, P., Banooei, A., and Abbasian Nigcheh, S. (2013). "Identifying the Effects of the Growth of Economic Sectors in Poverty Reduction Using the Coefficients of Incremental Fixed Price SAM ", Quarterly Journal of Economic Research and Development, Vol. 3 No. 10. PP. 27-40.

32. Son, H. (2003). "A New Poverty Decomposition", Journal of Economic Inequality 2:1-7.

33. Todaro, M. (2007). "Economic Development in the Third World". Translated by Farjaadi, Gholamali. Planning and Budget Organization, Vol. 1.

34. Verme.P. (2006). "A structural analysis of growth and poverty in the short-term". University of Torino and Bocconi Univercity, Italy.

35. White, H. and Anderson, E. (2001). "Growth versus Distribution: Does the Pattern of Growth Matter?" Development Policy Review 19:3 267-289.

36. Zarroki, S., Shahmiri, S.(2012), "Estimating the poverty line in Mazandaran province during the social and economic development plan of Iran", Quarterly Journal of Business Research, No. 64, Autumn 2012, 223-245. 
Figures

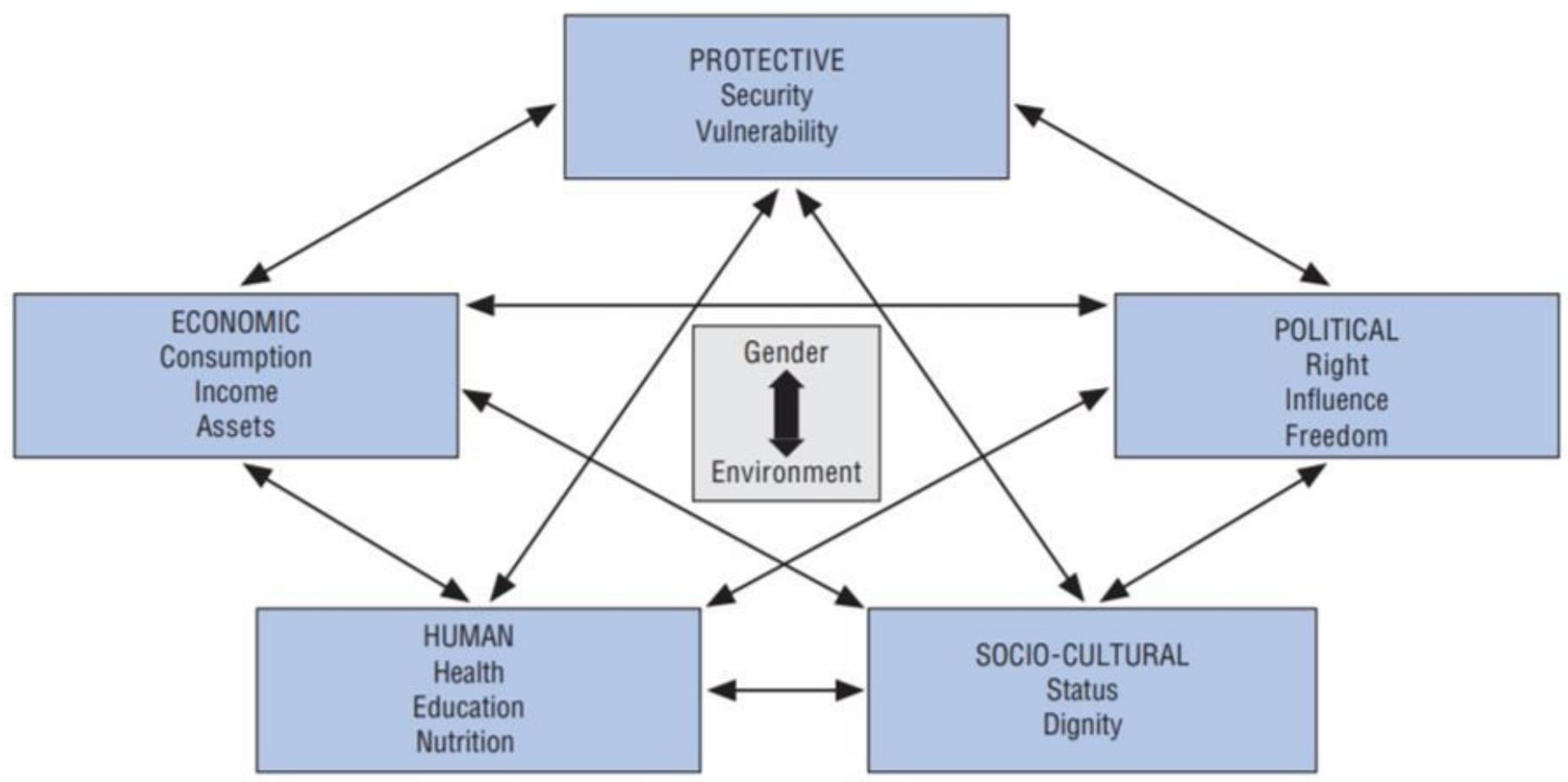

Figure 1

The multi-dimensional poverty framework Source: Maning and Smith, 2007 


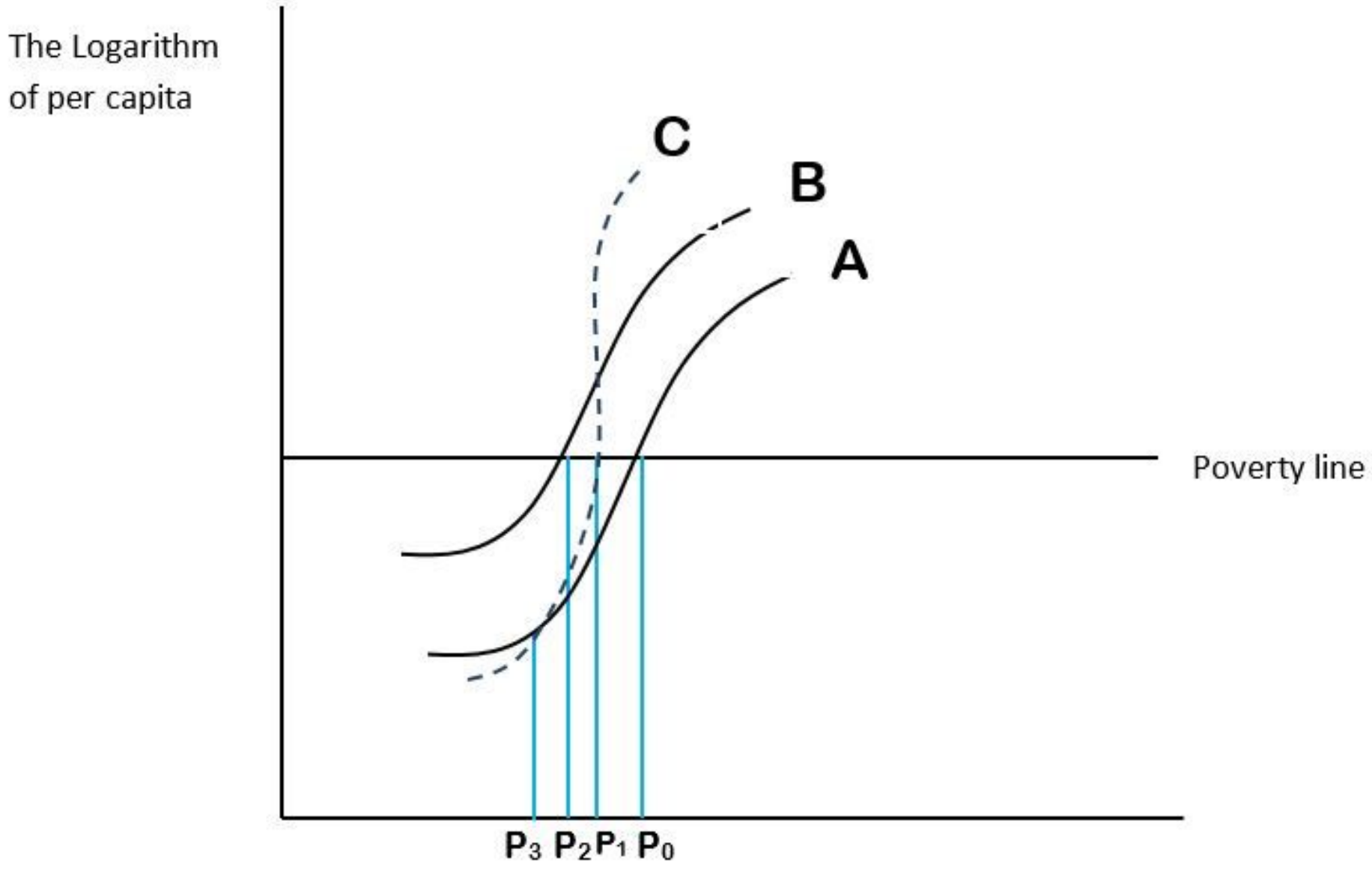

Figure 2

The relationship between poverty, inequality and growth Source: Jalilian and Patrick, 2005

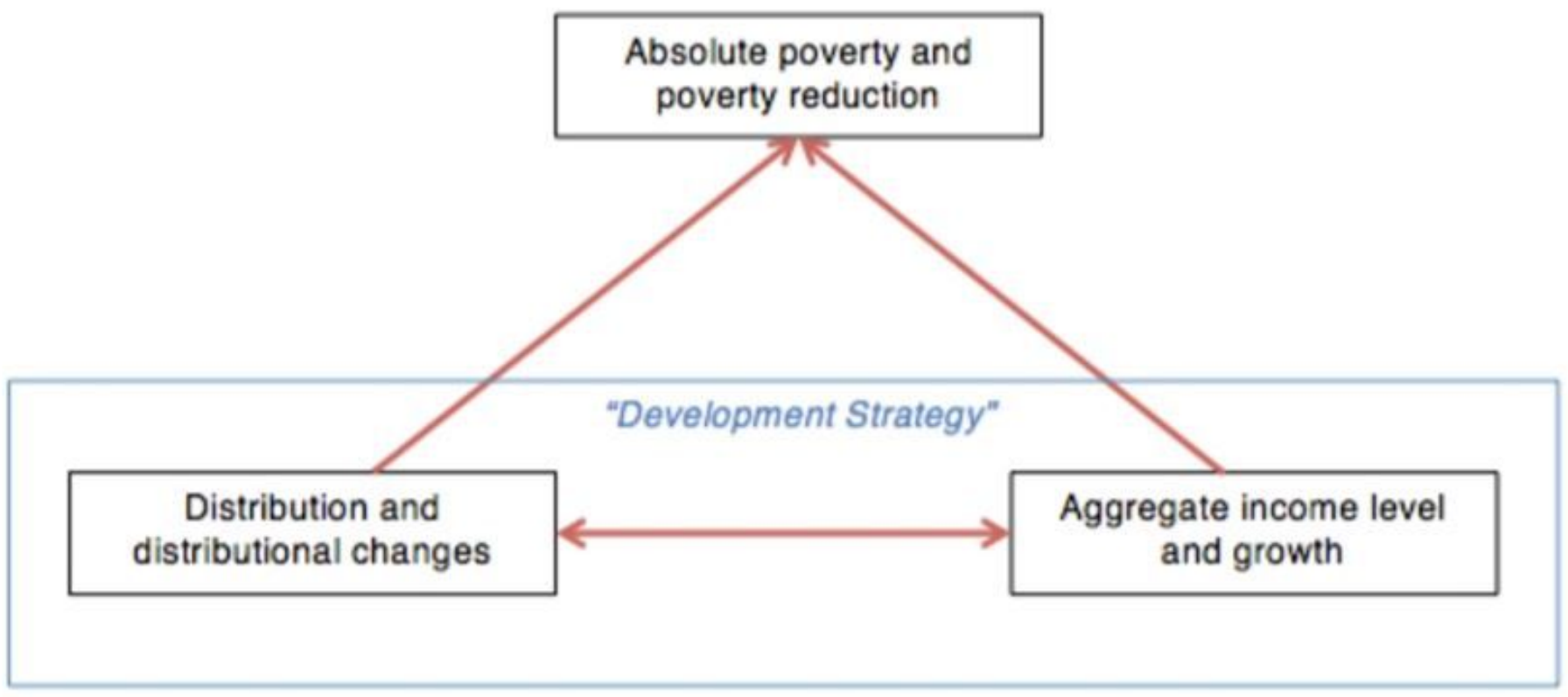


Figure 3

The poverty- inequality- growth triangle Source: Bourguinon, 2004

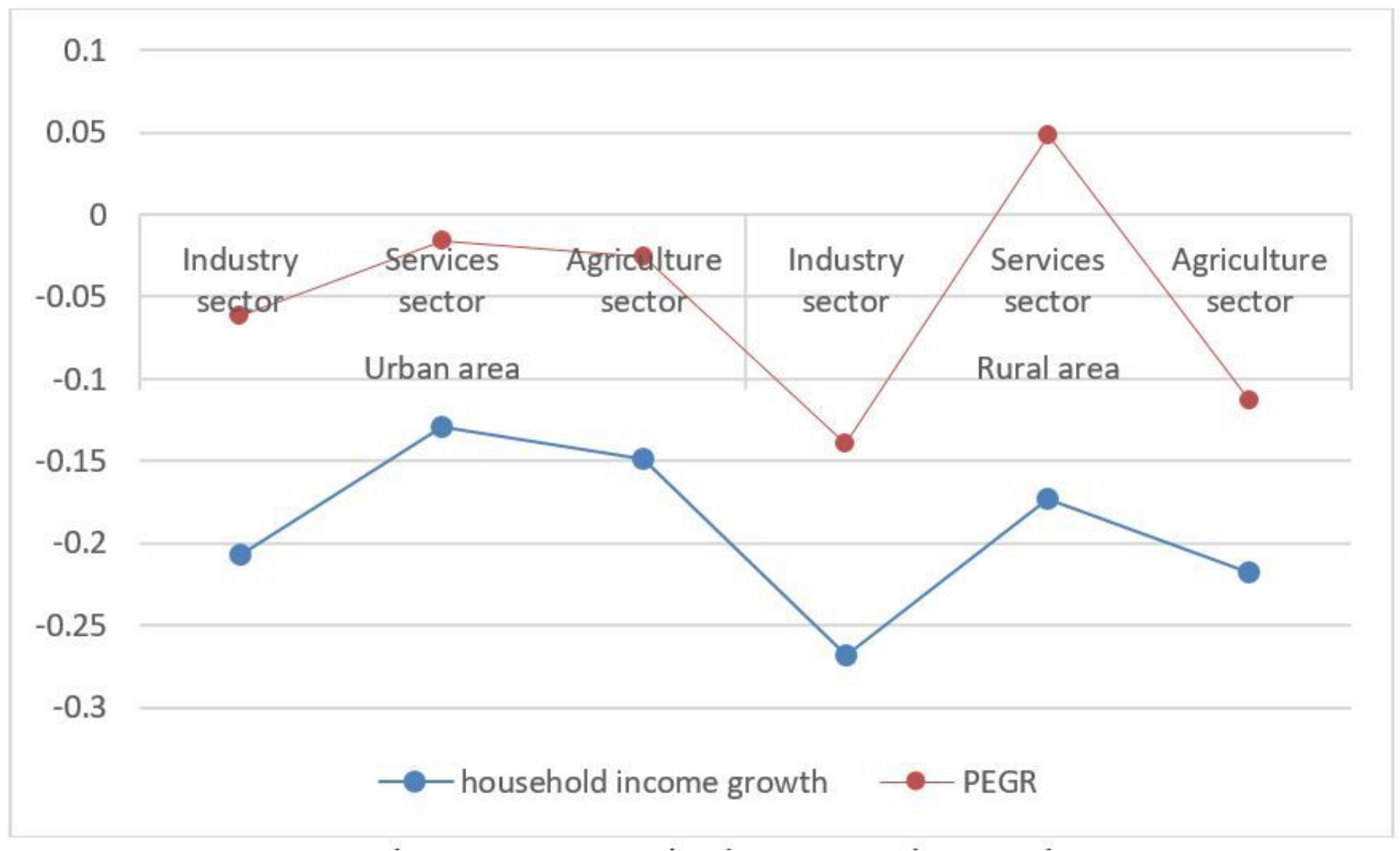

\section{Figure 4}

The poverty equivalent growth rates by sectors 


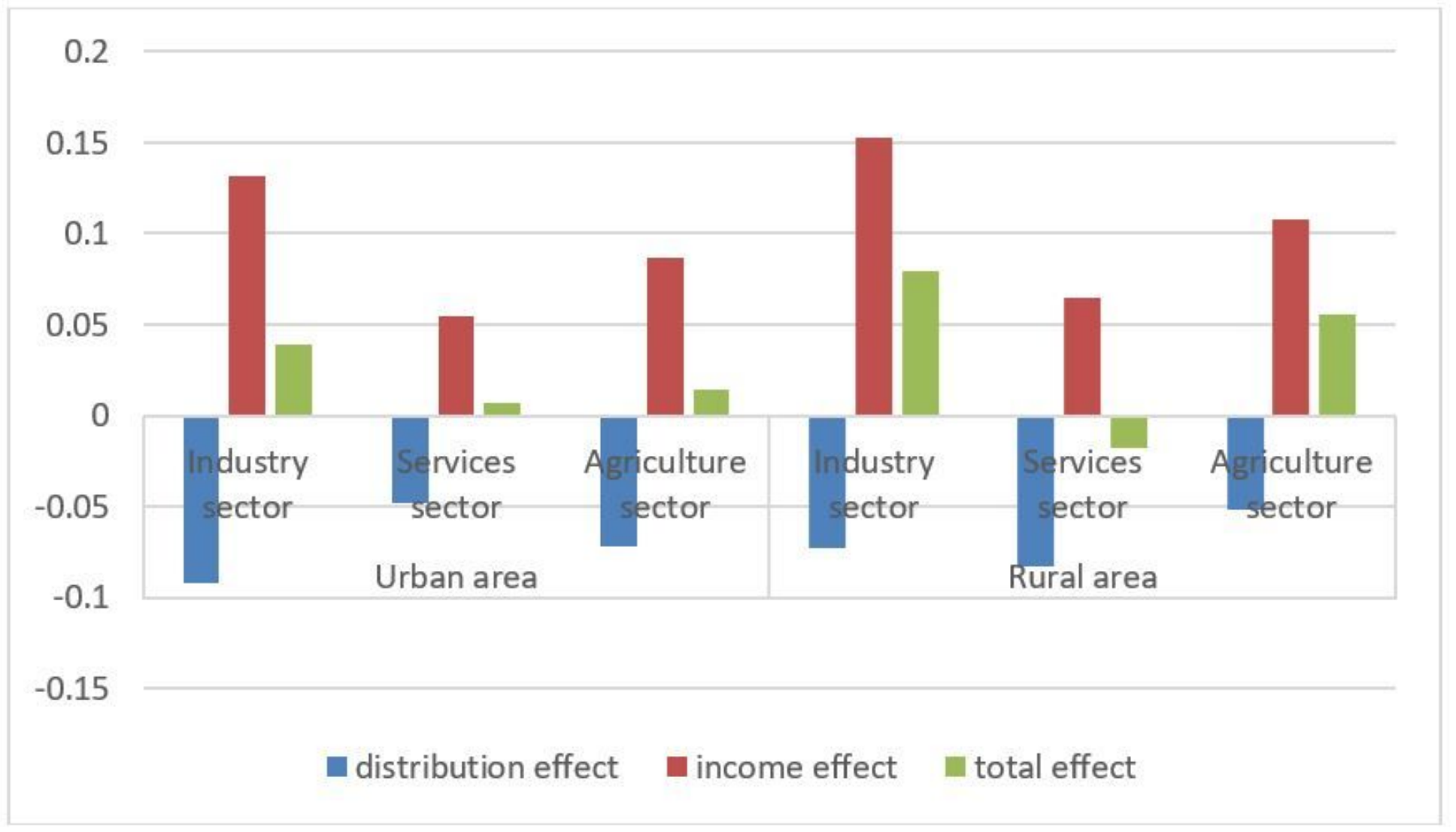

Figure 5

The poverty equivalent growth rates by sectors. 